\title{
Functions of Intermittent Locomotion in Mustached Tamarins (Saguinus mystax)
}

\author{
Mojca Stojan-Dolar • Eckhard W. Heymann
}

Received: 30 August 2009 /Revised: 9 January 2010 / Accepted: 9 January 2010 /

Published online: 29 June 2010

(C) The Author(s) 2010. This article is published with open access at Springerlink.com

\begin{abstract}
Many animals interrupt their moving with brief pauses, which appear to serve several different functions. We examined the function of such intermittent locomotion in wild living mustached tamarins (Saguinus mystax), small arboreal New World primates that form mixed-species groups with saddleback tamarins (Saguinus fuscicollis). We investigated how different environmental and social factors affect pausing during locomotion and used these data to infer the function of this behavior. As measures of intermittent locomotion, we used percentage of time spent pausing and pause rate. We considered 3 possible functions that are not mutually exclusive: increased endurance, route planning, and antipredator vigilance. Mustached tamarins spent on average (mean \pm SE) $55.1 \pm 1.0 \%$ of time pausing, which makes effective resource exploitation more time consuming and needs to be outweighed by correspondingly large benefits. Percentage of time spent pausing decreased in larger mixed-species groups vs. smaller mixed-species groups and decreased with height and in monkeys carrying infants. It was not affected by sex, age, spatial arrangement, or single-species group size. Pause rate increased in individuals traveling independently compared to those traveling in file, but was not affected by other factors. The group size effect in mixed-species groups lends support to the notion that pausing during locomotion is an antipredator tactic that can be reduced in the increased safety of larger groups, but other results suggest that additional functions, particularly route planning, are also of great importance. Benefits in terms of predator confusion and group movement coordination are also likely to play a role and remain a topic for further research.
\end{abstract}

M. Stojan-Dolar • E. W. Heymann

Department of Behavioral Ecology and Sociobiology, German Primate Center (DPZ),

Göttingen, Germany

M. Stojan-Dolar $(\bowtie)$

Department of Sociobiology/Anthropology, Georg-August-University of Göttingen, Kellnerweg 6,

37077 Göttingen, Germany

e-mail: mojca.stojan@arnes.si 
Keywords intermittent locomotion · mixed-species groups $\cdot$ Saguinus mystax vigilance

\section{Introduction}

Many animal species interrupt their moving with brief pauses. Examples include crabs (Girard et al. 2001; Weinstein 1995), lizards (Weinstein and Full 1999), marine mammals (Williams et al. 2000), and small rodents (McAdam and Kramer 1998; Trouilloud et al. 2004; Vasquez et al. 2002). Such intermittent locomotion has an important fitness cost because it increases the time needed to reach the next resource and therefore requires a functional explanation. It is thought to increase endurance, reduce detection by predators, enable animals to plan their journeys, and increase capacity of the sensory systems to detect relevant stimuli (Billat et al. 2000; Edwards and Gleeson 2001; Kramer and McLaughlin 2001; Vasquez et al. 2002; Weinstein and Full 2000). These functions are not mutually exclusive and are probably combined.

We investigated 3 possible functions of intermittent locomotion. First, pausing during anaerobic activity is likely to have endurance benefits, which researchers have studied in several different species such as crabs, iguana, mice, and humans (Billat et al. 2000; Girard et al. 2001; Hancock and Gleeson 2005; Pennisi 2000; Weinstein and Full 1992). During these short rests, lactate in the muscles can be reduced, which facilitates recovery from fatigue and prepares the muscles for the next bout of activity (Weinstein and Full 1992). As a result, the endurance of performance can be increased compared to continuous locomotion.

The second function that we investigated, route planning, is less often mentioned in the literature as a possible benefit of intermittent locomotion. However, moving through a complex and often dense environment such as rain forest demands a certain amount of planning, and because perception improves when gaze is stabilized (Avery 1993; Land 1999), we can expect intermittent locomotion to be at least partially related to orientation.

The third function of intermittent locomotion that we considered was vigilance. A large number of researchers have examined different aspects of vigilance in many animal taxa but used a number of different definitions of what constitutes vigilance. However, 2 features are central to most of these definitions: 1) they rely on head position or head movement of the observed animal and 2) they include only stationary animals (e.g. Cameron and du Toit 2005; Childress and Lung 2003; Ebensperger et al. 2006; Fernandez-Juricic et al. 2005; Jones 1998; Steenbeek et al. 1999; Treves 1998; Yáber and Herrera 1994). A vast majority of studies excluded locomoting animals, mostly because during locomotion head position is difficult to observe and a large proportion of scanning in this context may be dedicated to route planning. Vigilance while moving has received very little attention so far ( $c f$. Cowlishaw 1998; Hirsch 2002; van Schaik and van Noordwijk 1989), although animals may spend a notable amount of time in locomotion. It is reasonable to assume that some mechanism that reduces the probability of predator attack must be in place also during this time. Moreover, if an animal has reasons for social vigilance, they are also not likely to cease during locomotion. Studies on small rodents provide increasing evidence that pausing during locomotion serves a similar 
vigilance function as head raising in stationary animals (squirrels [Sciurus carolinensis] and chipmunks: McAdam and Kramer, 1998; chipmunks [Tamias striatus]: Trouilloud et al. 2004; degu [Octodon degus]: Vasquez et al. 2002).

We here examine the function of intermittent locomotion in mustached tamarins (Saguinus mystax), small arboreal New World primates that make frequent pauses when locomoting. They live in Amazonian rain forests and form groups of 1-4 adult males and 1-4 adult females (Löttker et al. 2004). Owing to their small body size they are subject to strong predation pressure, mostly by large raptors, but also by snakes and terrestrial predators such as ocelot (Leopardus pardalis) and tayra (Eira barbara) (Galef et al. 1976; Heymann 1990a; Oversluijs Vasquez and Heymann 2001; Peres 1993; Shahuano Tello et al. 2002; Terborgh 1983). They form stable mixed-species groups (MSG) with saddleback tamarins (Saguinus fuscicollis) in which the 2 species show vertical segregation with mustached living higher than saddleback tamarins (Heymann and Buchanan-Smith 2000). To our knowledge, this is the first primate study that addresses the adaptive significance of intermittent locomotion.

We investigated how different environmental and social factors affect intermittent locomotion in mustached tamarins at 2 different sites and used these data to infer the function of this behavior. We formed 3 sets of predictions based on different hypotheses for the predominant function of intermittent locomotion (Table I). First, if intermittent locomotion increases endurance, we expect that juveniles and animals carrying infants will pause more because they fatigue more quickly than adults or noncarriers. We expect that site, spatial arrangement, group size, sex (tamarins are monomorphic), and height are not related to endurance and would have no effect on pausing during locomotion.

Second, if the predominant function of intermittent locomotion is route planning, monkeys at a site with dense primary rain forest are expected to pause more than those at a site with more open secondary forest because of lower visibility in the former habitat. When traveling in file, all group members usually follow exactly the same path through the forest, so except for the leader of progression, they would be expected to pause less than when travelling independently (not in file). Also, when traveling independently, juveniles can be expected to pause more than adults because they lack experience in moving through the forest and do not know the environment as well as the adults do. Carriers should plan more carefully because they cannot leap across the same gaps that nonloaded individuals can, so they would need to pause more (Schradin and Anzenberger 2001). Pausing would also be expected to decrease with height because at higher levels there are more branches so monkeys can run continuously through the forest, while they have to leap from trunk to trunk when they are closer to the ground. Every leap is almost always preceded and followed by a brief pause (Heymann and Stojan-Dolar pers. obs.).

Third, predictions assuming that intermittent locomotion serves the same function as vigilance in stationary animals are based on results from our study on stationary vigilance (Stojan-Dolar and Heymann 2010). Just like vigilance in stationary animals, pausing during locomotion is expected to decrease in larger MSG due to the group size effect. In theory the group size effect could also be expected in singlespecies groups (SSG); however, this was not the case in our study on stationary vigilance. We hypothesized that this occurred due to increased scanning of group members as maintaining group cohesion becomes more challenging with increasing 


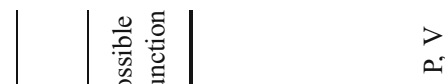

4

볼

F

.ั)

离

章

a

总

芩

苛

总

这

害

然

春宓 


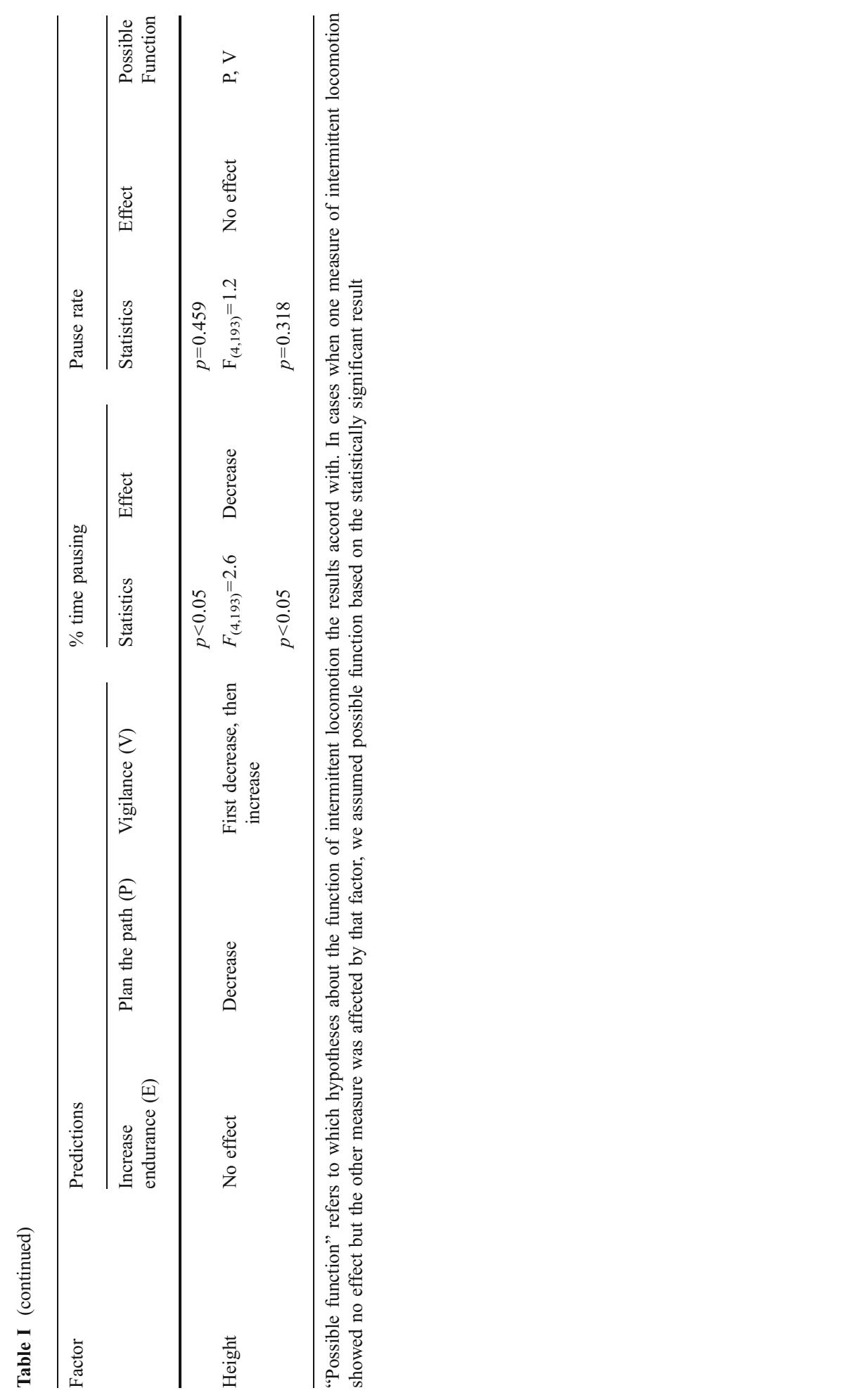


number of conspecifics in the group, which can cancel out the decrease of antipredator vigilance (MSG and SSG at the two study sites were of comparable sizes). Maintaining group cohesion is likely to be at least equally difficult when moving so our prediction is that if intermittent locomotion has the same function as vigilance in stationary animals it will also not be affected by SSG size. Alternatively, it is also possible that we did not detect a decline of vigilance with group size because of the absence of very small groups $(<5)$ where the group size effect should be strongest. Further, we predict that intermittent locomotion will first decrease and then increase with height because tamarins appear to perceive middle heights as safest (Stojan-Dolar and Heymann 2010). Close to the ground there might be a combined risk of attacks by terrestrial and sit-and-wait aerial predators, while high in the canopy proximity of aerial predators could represent a danger. Males would also pause more than females and carriers would pause more than noncarriers. Depending on the species, juveniles can be more vigilant, less vigilant, or show no difference compared to adults (Caro 2005). In our study populations adults and juveniles did not differ in their vigilance levels when stationary, so we predict no effect of age on intermittent locomotion. Although vigilance when feeding differed between the 2 study sites, this difference was presumably due to differences in how demanding the handling of food items was, which would not affect locomotion patterns. However, because raptors are mostly sit-and-wait predators that perch within canopies, monkeys in the habitat with low visibility would be expected to pause more (Boinski et al. 2000). It is difficult to predict the effect of spatial arrangement on pausing. Vigilance in stationary animals is known to decrease in proximity of other group members due to enhanced detection and dilution effects, which occurred also in our study population. On one hand, a similar pattern could be expected in locomoting animals where individuals moving independently would pause more because their distance to other group members is larger. On the other hand, animals traveling in file might pause more because they are much more conspicuous than those traveling independently. Also, pausing when travelling in file could increase because animals see when the individual in front pauses, which could alert them and cause them to stop as well to check the environment for potential predators. This effect would not be expected in animals moving independently.

\section{Methods}

Study Sites and Subjects

We studied wild mustached tamarins at 2 study sites in the northeastern lowlands of Peruvian Amazonia. The first site, Estación Biológica Quebrada Blanco (EBQB), is located $c a .70 \mathrm{~km}$ southeast of Iquitos $\left(4^{\circ} 21^{\prime} \mathrm{S}, 7^{\circ} 9^{\prime} \mathrm{W}\right)$ and is covered by primary tierra firme forest (Heymann 1995). M. Stojan-Dolar observed 3 well-habituated groups of mustached tamarins for 136 d between February 2006 and March 2007, covering both rainy and dry seasons. During the rainy season, she observed each group for 5-6 d every month and during the dry season she observed each group for 5-6 d every second month. The weighted mean group size \pm SE (relative to the proportion of time each group size and composition was observed) was $6.6 \pm 0.2$ 
(range: 5-9), including $2.9 \pm 0.2$ adult males (range: $2-5$ ) and $1.6 \pm 0.1$ adult females (range: 1-2). They formed stable mixed-species groups (MSG) with $5.1 \pm 0.3$ saddleback tamarins (range: 2-8).

The second location, Padre Isla (PI), is an approximately $8-\mathrm{km}^{2}$ island on the Amazon River near Iquitos (344'S, $\left.73^{\circ} 14^{\prime} \mathrm{W}\right)$ (Heymann 1990b). No primates originally lived on the island, but in 1977, 1978, and 1980, the Peruvian Primatological Project released a total of 87 wild-trapped mustached tamarins there (Ique 2000). The island is covered by seasonally flooded (January-May) secondary forest and fruit and vegetable plantations. The vegetation in the forest and fruit tree plantations is less dense, and trees are generally lower than in the primary forest at EBQB. Observations were possible only during the dry season.

There are human settlements on the island, so the animals in this population are used to human presence and researchers have occasionally followed the groups (Garber and Pruetz 1995; Garber et al. 1993; Heymann 1990b; Tornow et al. 2006). However, to minimize the potential problems resulting from comparing populations with different degrees of habituation, we followed the monkeys for 2 mo before starting the observations. After this additional habituation period, the monkeys did not pay more attention to observers than those at EBQB. M. Stojan-Dolar observed 2 groups of mustached tamarins for $63 \mathrm{~d}$ between August 2006 and January 2007. She observed each group for $c a$. $10 \mathrm{~d}$ every second month. The mean group size ( $\pm \mathrm{SE}$ ) was $10.8 \pm 0.7$ (range: $8-14$ ), including $2.4 \pm 0.5$ adult males (range: $1-5$ ) and $2.8 \pm$ 0.1 adult females (range: 2-3). Because no other primates are present, mustached tamarins on PI live in single-species groups (SSG). We individually identified individuals at both sites by differences in pelage patterns, body size and shape, and pigmentation of reproductive organs (Löttker et al. 2004).

Predation pressure at different sites could be different, which would influence vigilance and render the comparison difficult. Because it is not possible to measure predation pressure directly, we recorded alarm calls emitted by tamarins as a measure of perceived predation risk (Hill and Dunbar 1998). The rate of alarm calls did not differ between the sites $(0.33 \pm 0.23$ per $10 \mathrm{~h}$ of observation per individual for EBQB (mean $\pm \mathrm{SD}$ ) and $0.33 \pm 0.11$ for PI, Mann-Whitney $U: n_{1}=27 ; n_{2}=6 ; Z=-0.420 ; p=$ 0.674 ) so we were able to continue the analysis without controlling for perceived predation risk.

\section{Observation Methods}

We used continuous focal sampling (Martin and Bateson 1990) to record pauses during locomotion. We made observations on individuals that were moving in a clear direction and were not obviously engaged in social play. We defined pausing as an interruption in this forward movement. If an individual paused for $>15 \mathrm{~s}$ we discarded the observation because it could have switched to resting. Minimum pause length that we could record was 0.2 s. Observation conditions allowed for 30-120-s focal observations before the focal individual moved out of sight. We chose the focal individual based on which subjects were visible to maximize the amount of data collected. When there was a choice we chose the individual with the least observations, unless it had been the focal individual during the previous $30 \mathrm{~min}$. However, when individuals were moving in file, we never made observations on the 
leaders of progression. M. Stojan-Dolar entered data directly into a hand-held computer using The Observer Mobile ${ }^{\circledR}$. For each observation we recorded the following variables: individual identity, age class (juvenile: 6-12 mo, subadult: 13-18 mo, adult: $>18 \mathrm{mo}$ ), sex (f, m), height (ground, 0-3 m, 3-6 m, 6-9 m, 9$12 \mathrm{~m},>12 \mathrm{~m}$ when it did not change during the observation), total group size (= number of conspecifics + heterospecifics if present; we included only individuals $>3 \mathrm{mo}$ ), spatial arrangement (whether the focal individual was moving independently or in file) and whether the focal individual was carrying an infant. When conditions changed during an ongoing observation session, that session was stopped. We considered the 2 species as a MSG when $\geq 1$ individual from each species was within $<20 \mathrm{~m}$ (Struhsaker 1981).

\section{Data Analysis}

We used 2 measures of intermittent locomotion: percentage of time spent pausing and pause rate for every focal animal observation. To meet the requirements for parametric analysis, we arcsine transformed the percentages before we entered them in the analysis (Zar 1999). The data on pause rate were normally distributed and no transformation was needed. To avoid pseudoreplication, we analyzed the influence of each independent variable on each measure of intermittent locomotion using generalized linear mixed model (GLMM) with individual identity nested within group as a random factor. Owing to the nature of different independent variables, we had to use different data subsets to analyze the effect of individual variables (Table II) and therefore we could only use one-way models. Because animals at PI did not form MSG, we analyzed group size data separately for MSG at EBQB and for SSG at PI. For infant carrying we took data only from the periods when infants were present and visible. For the analysis of the effect of age we used only the observations that were done on individuals traveling independently because the prediction that juveniles will pause more if the predominant function of intermittent locomotion is route planning is not valid when traveling in file, as they can simply follow the individual in front. In the analyses of all other factors we used the

Table II Data sets used for analyses of effects of different factors on intermittent locomotion

\begin{tabular}{llllc}
\hline Factor & Data used & $\begin{array}{l}\text { Number (\%) of } \\
\text { observations }\end{array}$ & $\begin{array}{l}\text { No. } \\
\text { individuals }\end{array}$ & $\begin{array}{l}\text { No. of } \\
\text { groups }\end{array}$ \\
\hline Site & All & $343(100 \%)$ & 36 & 5 \\
Spatial arrangement & All & $343(100 \%)$ & 36 & 5 \\
Group size in SSG & Only Padre Isla & $199(58 \%)$ & 18 & 2 \\
Total MSG group size & Only MSG at Quebrada Blanco & $126(37 \%)$ & 14 & 3 \\
Sex & Adults only & $205(60 \%)$ & 23 & 5 \\
Age & Only observations when individuals & $174(51 \%)$ & 29 & 5 \\
Carrying infants & were not traveling in file & $198(58 \%)$ & 33 & 5 \\
Height & Only when infants $<3$ mo present in & & & 5 \\
\hline
\end{tabular}


complete data set. Because the percentage of time spent pausing during locomotion at EBQB and PI did not differ, we lumped the data from the 2 sites.

\section{Results}

When moving, mustached tamarins spent on average (mean \pm SE) $55.1 \pm 1.0 \%$ of time pausing. They paused on average $6.6 \pm 0.1 \mathrm{times} / \mathrm{min}$ and an average pause lasted $6.0 \pm 0.2 \mathrm{~s}$. Percentage of time spent pausing during locomotion decreased with height, in larger MSG, and when animals were carrying infants (Table I, Fig. 1). Spatial arrangement, SSG size, sex, and age did not affect percentage of time pausing. Because sex and height influenced vigilance in stationary individuals differently at EBQB and at PI (Stojan-Dolar and Heymann 2010), we reran the analyses for these factors with data separated by site. This revealed that height was a significant factor at $\operatorname{EBQB}(F(3,83)=7.8, p<0.001)$, but not at PI $(F(3,98)=0.6, p=$ $0.626)$. However, the analysis of the impact of sex rendered no significant results when divided by site (EBQB: $F(1,101)=0.7, p=0.407$; PI: $F(1,103)=0.3, p=0.612$ ). The only factor that affected pause rate was spatial arrangement: individuals moving independently paused more frequently than animals moving in file (Table I, Fig. 2).

\section{Discussion}

Intermittent locomotion appears to serve several different functions (Table I, Kramer and McLaughlin 2001). The analysis of factors affecting pausing during locomotion lends partial support for all the three hypotheses proposed in the introduction: increased endurance, route planning, and vigilance. In the primate literature, little attention has been devoted so far to intermittent locomotion as a possible vigilance strategy, but studies on small rodents provide increasing evidence that intermittent locomotion may serve the same function as vigilance in stationary animals (McAdam and Kramer 1998; Trouilloud et al. 2004; Vasquez et al. 2002). The result that most strongly suggests the vigilance function in the present study is the group size effect in MSG. Larger groups are safer due to collective vigilance (detection effect, Pulliam 1973) and reduced individual risk of being attacked (dilution effect, Hamilton 1971), and as a consequence individuals can decrease their antipredator behavior, be it stationary vigilance or intermittent locomotion. No effect of age and decrease of pausing with height also correspond with our findings in stationary individuals and — at least partially_ indicate that pauses may have a vigilance function.

Nevertheless, the relationship between vigilance and intermittent locomotion in mustached tamarins is not as strong as in rodents. The reasoning used in the rodent literature is that if the 2 behaviors have the same function, the factors that affect one behavior should also affect the other. However, in our study on vigilance in stationary animals we showed that in mustached tamarins stationary vigilance in different behavioral contexts (rest, feed, groom) is not influenced by the same set of factors (Stojan-Dolar and Heymann 2010) although it probably serves predator detection in all these contexts. We suggest that the same is true also for intermittent 
Fig. 1 Factors affecting the percentage of time spent pausing. Graphs represent the effect of (a) total mixed-species group size; (b) carrying infants; and (c) height of the focal individual. Only statistically significant $(p<0,05)$ effects are shown. Error bars represent SE. The asterisks indicate which Bonferroni pairwise comparisons rendered significant differences.
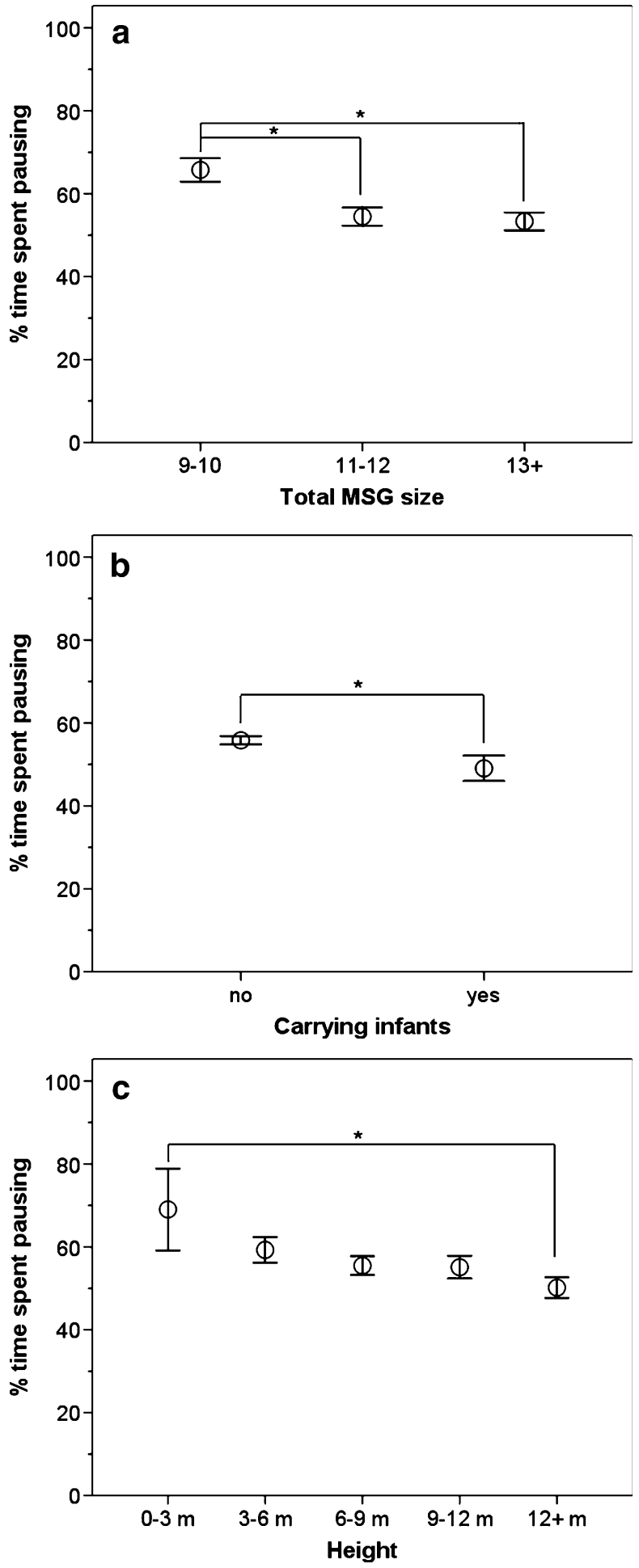


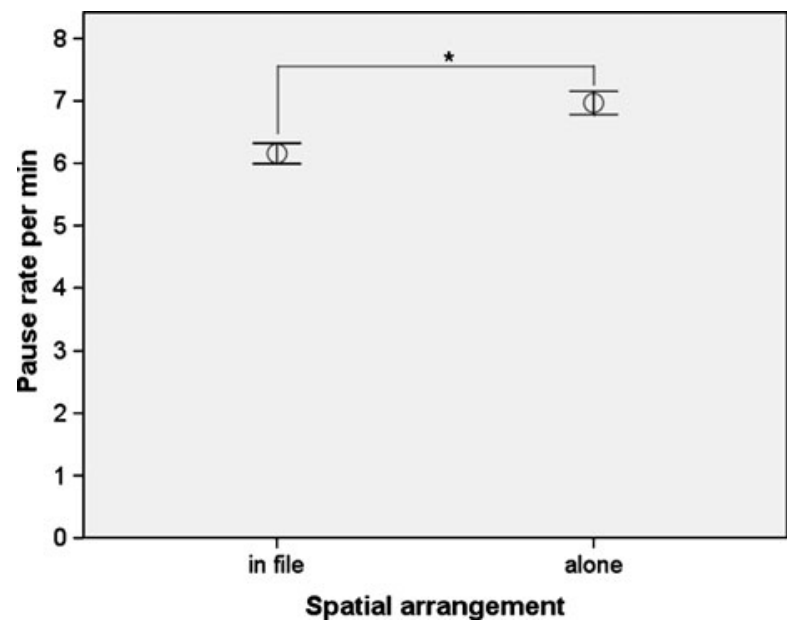

Fig. 2 Effect of spatial arrangement on pause rate. Other factors did not have a significant $(p<0,05)$ effect on the frequency of pausing. Error bars represent SE.

locomotion, but the expected effects are masked because nonpredator-related functions are of greater importance than in the case of vigilance in stationary individuals.

As small-bodied animals that are subject to considerable predation pressure, small rodents and mustached tamarins are likely to use vigilance as an important antipredator behavior and may be comparable to a certain extent. However, they differ in an important aspect. Unlike chipmunks and degus, tamarins live in a much more complex environment with denser vegetation and move around their habitat in all 3 dimensions. This probably requires more time for orientation and route planning. The idea that route planning is an important function of intermittent locomotion is supported by the fact that individuals paused more frequently when moving independently than when moving in file where they could simply follow the group mate in front. When moving independently, they apparently have to stop more often to make decisions on how to proceed, but they seem to have compensated for that by making pauses shorter so that the time spent pausing is not greater than when moving in file. Further, the percentage of time spent pausing decreased with height at EBQB like we predicted for rout planning hypothesis. The reason why height had no impact on intermittent locomotion at PI could be that the upper canopy at PI is more interrupted (Encarnación et al. 1990), so the monkeys have to leap also at greater heights.

In addition, a comparison of typical pause durations reveals that pausing bouts of mustached tamarins are 6-7 times longer than those of rodents (rodents: well under $1 \mathrm{~s}$ in all the above mentioned studies; tamarins: $6.0 \pm 0.2 \mathrm{~s}$ ), which implies that the monkeys probably do more than just a short check of the environment during this time. Another interesting observation, by Garber and Bicca-Marques (2002), is that when moving in file, all the group members that follow one another often pause at exactly the same spot. This could hardly be related to increased endurance or vigilance, but might mean that they stop at places where new decisions about the route need to be taken. 
The hypothesis that intermittent locomotion serves to increase endurance could not be unambiguously supported. It is possible that the monkeys were mostly not traveling above their maximum for aerobic capacity, although measuring the speed of travel was unfortunately not possible owing to difficult field conditions. The predicted effects were that juveniles would pause more than adults, which was not supported, and that carriers would pause more than noncarriers, which was contradicted. In fact, more pausing by noncarriers than carriers is a surprising result, as it contradicts all the suggested hypotheses. This could imply that it is not related to the 3 functions of intermittent locomotion, on which we based our predictions, but instead may be related to the speed of traveling. Because carriers have a heavy burden they are likely to move more slowly, and noncarriers may pause more to allow carriers to catch up. However, an interesting question that remains is why faster moving individuals would pause rather than slow down.

Thus pausing during locomotion could also contribute to coordination of group movement. This is especially challenging in MSG. When different species associate, conflicts of interests are more pronounced than in SSG and group coordination becomes more difficult (Cords 2000). Nevertheless, tamarin species appear to have a remarkable ability to coordinate activities and movements of the associating species (Buchanan-Smith 1990; Pook and Pook 1982; Terborgh 1983), which could be also due to intermittent locomotion. In addition to other possible functions, brief pauses enable animals to check the location of heterospecifics and allow them to catch up in case they are lagging behind. To examine this issue further, data on the percentage of time spent pausing in relation to the distance to the members of the associating species would be needed.

In addition to the functions discussed in the preceding text, intermittent locomotion can also reduce the conspicuousness of the prey if predators are more likely to detect animals that are moving (Martell and Dill 1995). Although this is likely to be important also for mustached tamarins, we did not consider this possibility because it is difficult to make predictions about the percentage of time spent pausing and pause rate. The aspects of intermittent locomotion that are likely to confuse predators are probably related to other parameters such as the irregularity and unpredictability of pausing, which we did not measure, but remain an interesting topic for future research. For similar reasons we also could not include prey foraging in our hypotheses. Although this is likely to be the reason for some of the longer pauses, it would be difficult to detect because looking for prey is not expected to depend on most of the factors measured in this study. Adults might search for insects more than juveniles, but there was no difference in intermittent locomotion between different age classes. Also, prey abundance may vary with height but because we do not have data on prey distribution, we cannot test whether the changes of intermittent locomotion with height result from differences in foraging activity in different forest strata.

Regardless of the function of intermittent locomotion, the fact that mustached tamarins spend more than half of their travel time motionless considerably slows down the travel speed and probably has important consequences for resource exploitation, as this means that a group can visit fewer food patches per day. In this context, a 55\% increase of travel time is certainly an important cost. Although diets of mustached and saddleback tamarins differ in the type of prey they consume, the 
degree of dietary overlap is higher in the fruit portion of the diet (Smith 2000), which suggests that - because many fruit trees do not have supra-abundant cropsscramble competition should increase in larger groups. As a consequence, more feeding trees should be visited to satiate all group members, which means that reduced travel efficiency due to pauses during locomotion may have posed a limitation in the evolution of tamarin group size (Wrangham et al. 1993). In the case of tamarins, this limitation is probably more important for the total MSG group size than for the number of conspecifics in a group because the latter is already strongly limited due to single-female breeding (Buchanan-Smith and Hardie 1997; Caine 1993).

In summary, mustached tamarins spend a high amount of time pausing during locomotion, which makes effective resource exploitation more time-consuming and needs to be outweighed by correspondingly large benefits, to which all the advantages considered here probably contribute. We found indications that this behavior serves a vigilance function to a certain extent but because they move in 3 dimensions through habitats with dense vegetation, a large proportion of pausing is probably dedicated to other functions, particularly route planning, rather than scanning the environment for potential danger. Benefits in terms of predator confusion and group movement coordination are also likely to play a role and remain a topic for further research. It is also important to note that different measures of intermittent locomotion (percentage of time spent pausing/pause rate) rendered very different results, which is likely to be the case also for other types of behavior. One should take this into account when planning future research and when comparing studies that use different methodologies.

Acknowledgments We thank the following people and organizations: Instituto Nacional de Recursos Naturales (INRENA) in Lima for research permits (authorization no. 018-2006-INRENA-IFFS-DCB); Instituto Veterinario de Investigaciones Tropicales y de Altura (IVITA) in Iquitos for permission to work at the biological station on Padre Isla; our field assistants Camilo Flores Amasifuen, Ney Shahuano Tello, and Manuel Shahuano Tello for their invaluable help in the forest; Dr. Carlos Ique for helpful practical advice; Yvan Lledo-Ferrer, Christian Matauschek, an anonymous reviewer, and Donald L. Kramer for helpful comments on previous versions of this manuscript; and Markus Port and other members of the Department of Behavioural Ecology and Sociobiology/Anthropology of the German Primate Center for many fruitful discussions. Financial support was partially provided by Deutscher Akademischer Austauschdienst (DAAD). Field work complied with Peruvian laws.

Open Access This article is distributed under the terms of the Creative Commons Attribution Noncommercial License which permits any noncommercial use, distribution, and reproduction in any medium, provided the original author(s) and source are credited.

\section{References}

Avery, R. (1993). Experimental analysis of lizard pause-travel movement: Pauses increase probability of prey capture. Amphibia-Reptilia, 14(4), 423-427.

Billat, V. L., Slawinski, J., Bocquet, V., Demarle, A., Lafitte, L., Chassaing, P., et al. (2000). Intermittent runs at the velocity associated with maximal oxygen uptake enables subjects to remain at maximal oxygen uptake for a longer time than intense but submaximal runs. European Journal of Applied Physiology and Occupational Physiology, 81(3), 188-196.

Boinski, S., Treves, A., \& Chapman, C. A. (2000). A critical evaluation of the influence of predators on primates: Effects on group travel. In S. Boinski \& P. A. Garber (Eds.), On the move: How and why animals travel in groups (pp. 43-72). Chicago: University Chicago Press. 
Buchanan-Smith, H. M. (1990). Polyspecific association of two tamarin species, Saguinus labiatus and Saguinus fuscicollis, in Bolivia. American Journal of Primatology, 22(3), 205-214.

Buchanan-Smith, H. M., \& Hardie, S. M. (1997). Tamarin mixed-species groups: An evaluation of a combined captive and field approach. Folia Primatologica, 68(3-5), 272-286.

Caine, N. G. (1993). Flexibility and co-operation as unifying themes in Saguinus social organization and behaviour: The role of predation pressures. In A. B. Rylands (Ed.), Marmosets and tamarins: Systamatics, behaviour, and ecology (pp. 200-219). Oxford: Oxford University Press.

Cameron, E. Z., \& du Toit, J. (2005). Social influences on vigilance behaviour in giraffes, Giraffa camelopardalis. Animal Behaviour, 69, 1337-1344.

Caro, T. (2005). Antipredator defenses in birds and mammals. Chicago: University of Chicago Press.

Childress, M. J., \& Lung, M. A. (2003). Predation risk, gender and the group size effect: Does elk vigilance depend upon the behaviour of conspecifics? Animal Behaviour, 66(2), 389-398.

Cords, M. (2000). Mixed species association and group movement. In S. Boinski \& P. A. Garber (Eds.), On the move: How and why animals travel in groups (pp. 73-99). Chicago: University of Chicago Press.

Cowlishaw, G. (1998). The role of vigilance in the survival and reproductive strategies of desert baboons. Behaviour, 135(4), 431-452.

Ebensperger, L. A., Hurtado, M. A. J., \& Ramos-Jiliberto, R. (2006). Vigilance and collective detection of predators in degus (Octodon degus). Ethology, 112(9), 879-887.

Edwards, E. B., \& Gleeson, T. T. (2001). Can energetic expenditure be minimized by performing activity intermittently? The Journal of Experimental Biology, 204(3), 599-605.

Encarnación, F., Aquino, R., \& Moro, J. (1990). Flora y vegetación de la Isla Iquitos y Padre Isla (Loreto, Perú): su relación con el manejo semiextensivo de Saguinus mystax, Saimiri sciureus y Aotus. In N. Castro Rodríguez (Ed.), La Primatología en el Peru. Investigaciones primatológicas (1973-1985) (pp. 475-488). Lima: Imprenta Propaceb.

Fernandez-Juricic, E., Smith, R., \& Kacelnik, A. (2005). Increasing the costs of conspecific scanning in socially foraging starlings affects vigilance and foraging behaviour. Animal Behaviour, 69, 73-81.

Galef, B. G., Mittermeier, R. A., \& Bailey, R. C. (1976). Predation by tayra (Eira barbara). Journal of Mammalogy, 57(4), 760-761.

Garber, P. A., \& Bicca-Marques, J. C. (2002). Evidence of predator sensitive foraging and traveling in single- and mixed-species tamarin troops. In L. E. Miller (Ed.), Eat or be eaten: Predator sensitive foraging among primates (pp. 138-153). New York: Cambridge University Press.

Garber, P. A., \& Pruetz, J. D. (1995). Positional behavior in moustached tamarin monkeys-effects of habitat on locomotor variability and locomotor stability. Journal of Human Evolution, 28(5), 411426.

Garber, P. A., Pruetz, J. D., \& Isaacson, J. (1993). Patterns of range use, range defense, and intergroup spacing in moustached tamarin monkeys (Saguinus mystax). Primates, 34(1), 11-25.

Girard, I., McAleer, M. W., Rhodes, J. S., \& Garland, T. (2001). Selection for high voluntary wheelrunning increases speed and intermittency in house mice (Mus domesticus). The Journal of Experimental Biology, 204(24), 4311-4320.

Hamilton, W. D. (1971). Geometry for the selfish herd. Journal of Theoretical Biology, 31, $295-311$.

Hancock, T. V., \& Gleeson, T. T. (2005). Intermittent locomotor activity that increases endurance also increases metabolic costs in the desert iguana (Dipsosaurus dorsalis). Physiological and Biochemical Zoology, 78(2), 163-172.

Heymann, E. W. (1990a). Reactions of wild tamarins, Saguinus mystax and Saguinus fuscicollis to avian predators. International Journal of Primatology, 11, 327-337.

Heymann, E. W. (1990b). Social behaviour and infant carrying in a group of moustached tamarins, Saguinus mystax (Primates: Platyrrhini: Callitrichidae), on Padre Isla, Peruvian Amazonia. Primates, 31, 183-196.

Heymann, E. W. (1995). Sleeping habits of tamarins, Saguinus mystax and Saguinus fuscicollis (Mammalia; Primates; Callitrichidae), in north-eastern Peru. Journal of Zoology, 237(2), 211-226.

Heymann, E. W., \& Buchanan-Smith, H. M. (2000). The behavioural ecology of mixed-species troops of callitrichine primates. Biological Reviews of the Cambridge Philosophical Society, 75(2), 169-190.

Hill, R. A., \& Dunbar, R. I. M. (1998). An evaluation of the roles of predation rate and predation risk as selective pressures on primate grouping behaviour. Behaviour, 135, 411-430.

Hirsch, B. T. (2002). Social monitoring and vigilance behavior in brown capuchin monkeys (Cebus apella). Behavioral Ecology and Sociobiology, 52(6), 458-464.

Ique, C. (2000). Manejo semi-extensivo de Saguinus mystax en Padre Isla, río Amazonas. In F. Howard \& M. García Podestá (Eds.), La Primatología en el Perú 2 (pp. 131-143). Lima: Master Graf Editores. 
Jones, M. E. (1998). The function of vigilance in sympatric marsupial carnivores: The eastern quoll and the Tasmanian devil. Animal Behaviour, 56(5), 1279-1284.

Kramer, D. L., \& McLaughlin, R. L. (2001). The behavioral ecology of intermittent locomotion. American Zoologist, 41(2), 137-153.

Land, M. F. (1999). Motion and vision: Why animals move their eyes. Journal of Comparative Physiology A - Neuroethology Sensory Neural and Behavioral Physiology, 185(4), 341-352.

Löttker, P., Huck, M., \& Heymann, E. W. (2004). Demographic parameters and events in wild moustached tamarins (Saguinus mystax). American Journal of Primatology, 64(4), 425-449.

Martell, G., \& Dill, L. M. (1995). Influence of movement by coho salmon (Oncorhynchus kisutch) parr on their detection by common mergansers (Mergus merganser). Ethology, 99, 139-149.

Martin, P., \& Bateson, P. (1990). Measuring behaviour - an introductory guide. Cambridge: Cambridge University Press.

McAdam, A. G., \& Kramer, D. L. (1998). Vigilance as a benefit of intermittent locomotion in small mammals. Animal Behaviour, 55(1), 109-117.

Oversluijs Vasquez, M. R., \& Heymann, E. W. (2001). Crested eagle (Morphnus guianensis) predation on infant tamarins (Saguinus mystax and Saguinus fuscicollis, Callitrichinae). Folia Primatologica, 72(5), 301-303.

Pennisi, E. (2000). In nature animals that stop and start win the race. Science, 288(5463), 83-85.

Peres, C. A. (1993). Anti-predation benefits in a mixed-species group of Amazonian tamarins. Folia Primatologica, 61(2), 61-76.

Pook, A. G., \& Pook, G. (1982). Polyspecific association between Saguinus fuscicollis, Saguinus labiatus, Callimico goeldii and other primates in north-western Bolivia. Folia Primatologica, 38(3-4), 196216.

Pulliam, H. R. (1973). On advantages of flocking. Journal of Theoretical Biology, 38, 419-422.

Schradin, C., \& Anzenberger, G. (2001). Costs of infant carrying in common marmosets, Callithrix jacchus: An experimental analysis. Animal Behaviour, 62(2), 289-295.

Shahuano Tello, N., Huck, M., \& Heymann, E. W. (2002). Boa constrictor attack and successful group defence in moustached tamarins, Saguinus mystax. Folia Primatologica, 73(2-3), 146-148.

Smith, A. C. (2000). Interspecific differences in prey captured by associating saddleback (Saguinus fuscicollis) and moustached (Saguinus mystax) tamarins. Journal of Zoology, 251(3), 315-324.

Steenbeek, R., Piek, R., van Buul, M., \& van Hooff, J. A. R. A. M. (1999). Vigilance in wild Thomas's langurs (Presbytis thomasi): The importance of infanticide risk. Behavioral Ecology and Sociobiology, 45(2), 137-150.

Stojan-Dolar, M., \& Heymann, E. W. (2010). Vigilance in a cooperatively breeding primate. International Journal of Primatology, 31(1), 95-116.

Struhsaker, T. T. (1981). Polyspecific associations among tropical rainforest primates. Zeitschrift Für Tierpsychologie, 57(3-4), 268-304.

Terborgh, J. (1983). Five New World primates: A study in comparative ecology. Princeton: Princeton University Press.

Tornow, M. A., Ford, S. M., Garber, P. A., \& Sauerbrunn, E. D. (2006). Dentition of moustached tamarins (Saguinus mystax mystax) from Padre Isla, Peru, part 1: Quantitative variation. American Journal of Physical Anthropology, 130(3), 352-363.

Treves, A. (1998). The influence of group size and neighbors on vigilance in two species of arboreal monkeys. Behaviour, 135(4), 453-481.

Trouilloud, W., Delisle, A., \& Kramer, D. L. (2004). Head raising during foraging and pausing during intermittent locomotion as components of anitipredator vigilance in chipmunks. Animal Behaviour, 67, 789-797.

van Schaik, C. P., \& van Noordwijk, M. A. (1989). The special role of male Cebus monkeys in predation avoidance and its effect on group composition. Behavioral Ecology and Sociobiology, 24, 265276.

Vasquez, R. A., Ebensperger, L. A., \& Bozinovic, F. (2002). The influence of habitat on travel speed, intermittent locomotion, and vigilance in a diurnal rodent. Behavioural Ecology, 13(2), 182-187.

Weinstein, R. B. (1995). Locomotor behavior of nocturnal ghost crabs on the beach-focal animal sampling and instantaneous velocity from 3-dimensional motion analysis. The Journal of Experimental Biology, 198(4), 989-999.

Weinstein, R. B., \& Full, R. J. (1992). Intermittent exercise alters endurance in an 8-legged ectotherm. The American Journal of Physiology, 262(5), R852-R859.

Weinstein, R. B., \& Full, R. J. (1999). Intermittent locomotion increases endurance in a gecko. Physiological and Biochemical Zoology, 72(6), 732-739. 
Weinstein, R. B., \& Full, R. J. (2000). Intermittent locomotor behaviour alters total work. In P. Domenici \& R. W. Blake (Eds.), Biomechanics in animal behaviour (pp. 33-48). Oxford: BIOS Scientific.

Williams, T. M., Davis, R. W., Fuiman, L. A., Francis, J., Le Boeuf, B. L., Horning, M., et al. (2000). Sink or swim: Strategies for cost-efficient diving by marine mammals. Science, 288(5463), 133-136.

Wrangham, R. W., Gittleman, J. L., \& Chapman, C. A. (1993). Constraints on group size in primates and carnivores: Population density and day-range as assays of exploitation competition. Behavioral Ecology and Sociobiology, 32(3), 199-209.

Yáber, M. C., \& Herrera, E. A. (1994). Vigilance, group-size and social status in capybaras. Animal Behaviour, 48(6), 1301-1307.

Zar, J. (1999). Biostatistical analysis. Upper Saddle River: Prentice-Hall. 